\title{
CHARACTERISTICS AND APPLICATIONS OF AMORPHOUS COMPOUND FLUID
}

\author{
Kunio SHIMADA *, Hitoshi NISHIDA **, Eiichiro YUZE *** and Yaoyang Zheng * \\ * Department of Symbiotic Systems Sciences, Fukushima University, \\ Kanayagawa 1, Fukushima 960-1296, Japan \\ (E-mail: shimadakun@sss.fukushima-u.ac.jp) \\ ** Department of Mechanical Engineering, Toyama National College of Technology, \\ 13 Hongo, Toyama, 939-8630, Japan \\ *** Akita Prefectural Industrial Technology Center, \\ 9-3, Furudate, Kosaka, Kazuno-gun, 017-0202
}

\begin{abstract}
We proposed an amorphous compound fluid (ACF) as a new intelligent or smart fluid. This fluid contains nm-size magnetite and $1 \mu \mathrm{m}$-sized amorphous particles in a solvent. This report shows, first, experimental data regarding the viscosity of ACF in a cone-type rotating rheometer under a transverse magnetic field and its magnetization under a DC magnetic field. The experimental results are then compared with those for previous magnetic responsive fluids, magnetic compound fluid (MCF), magneto-rheological fluid (MRF), and magnetic fluid (MF). Those magnetic clusters as aggregated particles were investigated by optical observation. Finally, this report shows the experimental results of engineering applications on polishing that utilize the ACF, and compares the results with polishing that utilizes MCF.
\end{abstract}

\section{KEY WORDS}

Amorphous, Magnetic Compound Fluid (MCF), Magnetic Fluid, Magnetic Field, Magneto-rheological Fluid

\section{NOMENCLATURE}

$R a:$ mean surface roughness

$R y$ : height of surface roughness between maximum and minimum heights

\section{INTRODUCTION}

A few intelligent fluids are responsive to magnetic fields, for example, magnetic fluid (MF) and magneto-rheological fluid (MRF). Both fluids have advantages and disadvantages in engineering applications [1]. MF's magnetization and apparent viscosity under a magnetic field is smaller than those of
MRF. However, the stability of the particle distribution in an MF solvent is more consistent than that in an MRF solvent. In light of this and for the purpose of producing a new intelligent or smart fluid, one of authors of the present paper, Shimada, has proposed a magnetic compound fluid (MCF) comprised of nm-size magnetite and $\mu \mathrm{m}$-size iron particles in a solvent, which thereby compounds MF and MRF [2]. He has measured the relation of its shear stress to its shear rate using a rotating rheometer $[2,3]$ and has also measured its magnetic characteristics [4]. He has also proposed new engineering applications that utilize MCF, for example, in polishing [5,6] or in a damper [7].

For the same purposes, we propose a magnetic 
responsive fluid containing amorphous particles: amorphous compound fluid (ACF) is comprised of $1 \mu \mathrm{m}$ order-sized amorphous particles and MF. In general, the material properties of the amorphous particles are different from those of the magnetite and iron particles regarding stiffness, large magnetization, etc. Therefore, if the amorphous particles are used in a solvent, the possibility of its having engineering applications different from the use of MCF alone can be expected. In the present paper, we first investigated the magnetic and rheological characteristics of ACF and compared them to those of MCF, MF, and MRF. Secondly, we investigated the potential engineering applications of $\mathrm{ACF}$ in polishing.

\section{ACF}

We used Co-P amorphous particles (C166) of about $1 \mu \mathrm{m}$ mean diameter that were fabricated and patented in Japan by Yuze [8], one of the present authors. We compounded the kerosene-based MF of HC50 with $1.29 \mathrm{~g}$ of $50 \mathrm{wt} \%$ of $10 \mathrm{~nm}$ mean diameter $\mathrm{Fe}_{3} \mathrm{O}_{4}$ produced by Taiho Industry Co. Ltd. in Japan and $2 \mathrm{~g}$ of amorphous particles (C166) composed of $\mathrm{C} 166$ at 60.8 $\mathrm{wt} \%, \mathrm{Fe}_{3} \mathrm{O}_{4}$ at $18.0 \mathrm{wt} \%$ and kerosene at $21.2 \mathrm{wt} \%$.

\section{MAGNETIC CHARACTERISTICS}

We investigated the magnetization of ACF under a DC magnetic field using a VSM (VSM-5S-15, Toei Ind. Co. Ltd., Japan). The experimental results are shown in
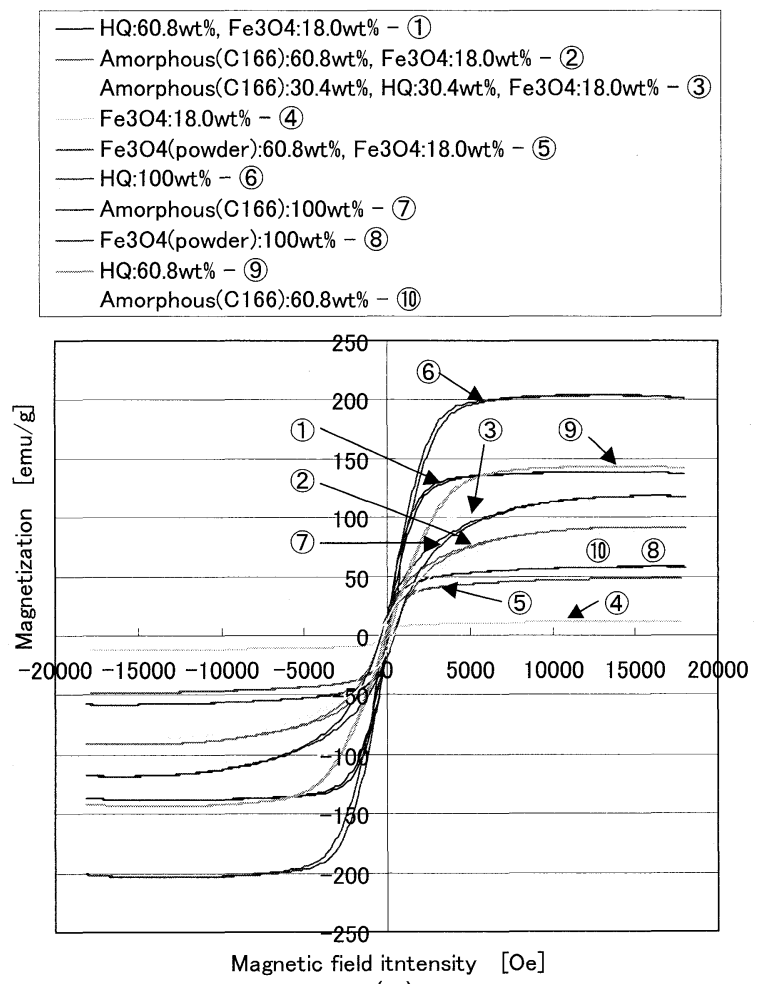

(a)

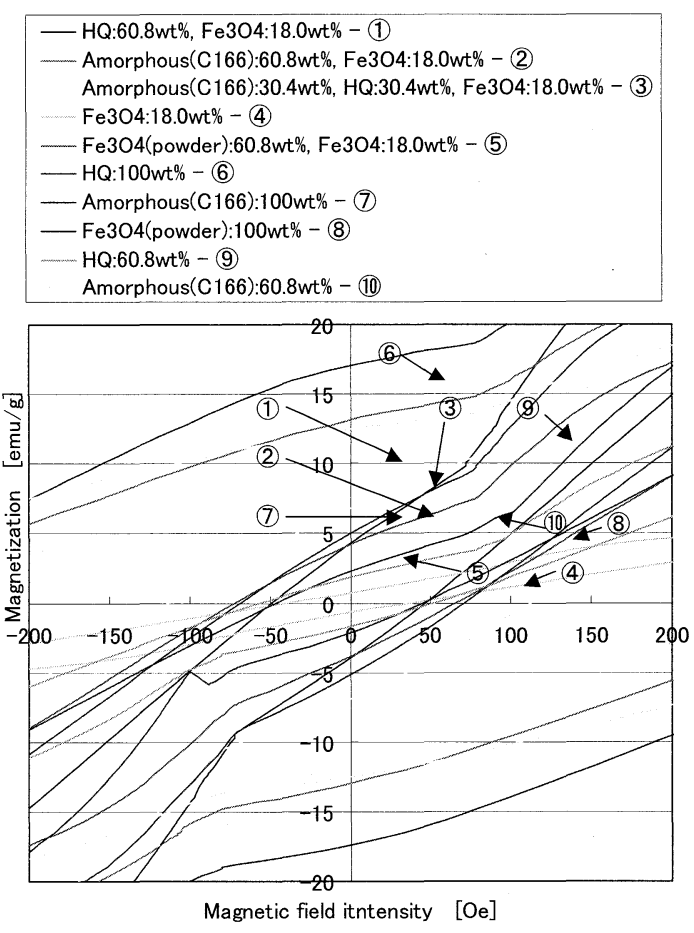

(b) detail at small magnetic field intensity of (a) Figure 1 Magnetization of ACF and the others

Table 1 Composite and data of magnetization of ACF, $\mathrm{MCF}, \mathrm{MRF}$ and MF

\begin{tabular}{|c|c|c|c|}
\hline $\begin{array}{l}\text { Mass concentration } \\
(\mathrm{wt} \%) \text { of testing } \\
\text { fluid }\end{array}$ & Material & Compound & $\begin{array}{l}\text { Residual } \\
\text { magnetiza- } \\
\text { tion } \\
{[\mathrm{emu} / \mathrm{g}]}\end{array}$ \\
\hline $\begin{array}{l}\mathrm{HQ}: 60.8, \mathrm{Fe}_{3} \mathrm{O}_{4}: \\
\text { 18.0, other } \\
\text { kerosene }\end{array}$ & $\mathrm{MCF}$ & $\mathrm{MRF}+\mathrm{MF}$ & 4.851 \\
\hline $\begin{array}{ll}\mathrm{C} 166: 60.8, & \mathrm{Fe}_{3} \mathrm{O}_{4}: \\
18.0, & \text { other } \\
\text { kerosene } & \\
\end{array}$ & $\mathrm{ACF}$ & $\begin{array}{c}\text { amorphous } \\
\text { particle } \\
+\mathrm{MF}\end{array}$ & 13.05 \\
\hline $\begin{array}{l}\text { C166: 30.4, HQ: } \\
\text { 30.4, } \mathrm{Fe}_{3} \mathrm{O}_{4}: 18.0 \text {, } \\
\text { other kerosene }\end{array}$ & $\mathrm{AMCF}$ & $\mathrm{ACF}+\mathrm{MCF}$ & 7.003 \\
\hline $\begin{array}{l}\mathrm{Fe}_{3} \mathrm{O}_{4}: 18.0 \text {, other } \\
\text { kerosene }\end{array}$ & $\mathrm{MF}$ & & 1.015 \\
\hline $\begin{array}{l}\mathrm{Fe}_{3} \mathrm{O}_{4} \text { (powder): } \\
60.8, \mathrm{Fe}_{3} \mathrm{O}_{4} \text { (from } \\
\text { the particles of } \\
\mathrm{MF} \text { ): 18.0, other } \\
\text { kerosene }\end{array}$ & & $\begin{array}{c}\text { powder of } \\
\mathrm{Fe}_{3} \mathrm{O}_{4}+\mathrm{MF}\end{array}$ & 4.394 \\
\hline HQ: 100 & powder & & 2.493 \\
\hline C166: 100 & powder & & 16.74 \\
\hline $\mathrm{Fe}_{3} \mathrm{O}_{4}: 100$ & powder & & 5.669 \\
\hline $\begin{array}{l}\text { HQ: } 60.8, \text { other } \\
\text { kerosene }\end{array}$ & $\mathrm{MRF}$ & & 1.827 \\
\hline $\begin{array}{l}\text { C166: } 60.8 \text {, other } \\
\text { kerosene }\end{array}$ & $\mathrm{AF}$ & & 12.48 \\
\hline
\end{tabular}


Fig. 1 and compared to those of MCF, MRF, MF, and powder. The caption in the figure is shown in Table 1 in detail. " $\mathrm{Fe}_{3} \mathrm{O}_{4}$ " in the figure means the magnetite in $\mathrm{MF}$, "powder" the particles only and "HQ" the carbonyl iron having $1.2 \mu \mathrm{m}$ of mean diameter made by BASF Co. Ltd. AMCF means the compounded fluids of ACF and $\mathrm{MCF}$, which we call "Amorphous Magnetic Compound Fluid". AF means the fluid having only amorphous particles of C166, which we call "Amorphous Fluid".

The magnetic property obtained from Fig. 1 is also shown in Table 1. The saturation magnetization is defined by that of the involved particles. That of ACF is smaller than that of MCF. Therefore, the order of the saturation magnetization is $\mathrm{MRF}>\mathrm{MCF}>\mathrm{AMCF}>\mathrm{ACF}>$ MF.

The residual magnetizations and the areas of the hysterisis loops of ACF and amorphous particles are much larger than those of $\mathrm{MCF}, \mathrm{MRF}, \mathrm{Fe}_{3} \mathrm{O}_{4}$, and $\mathrm{HQ}$.

\section{HYDRODYNAMIC CHARACTERISTICS}

We examined the viscosity using cone-type rotating rheometers under a uniform magnetic field. The magnetic field was applied transversely to the lower plate. Details of the experimental apparatus were

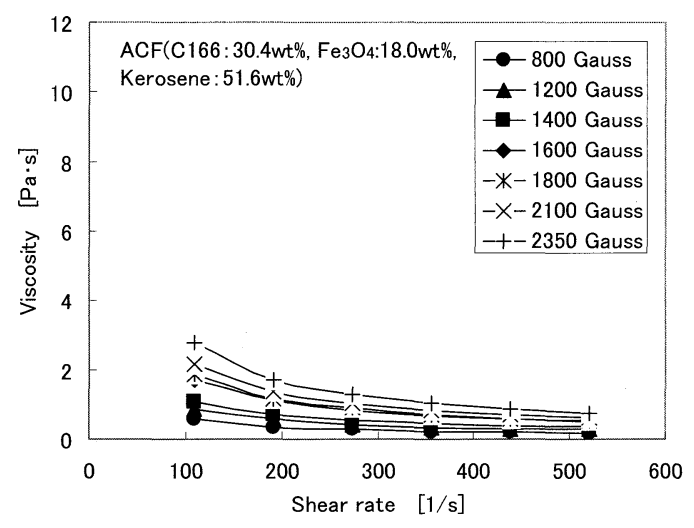

(a)

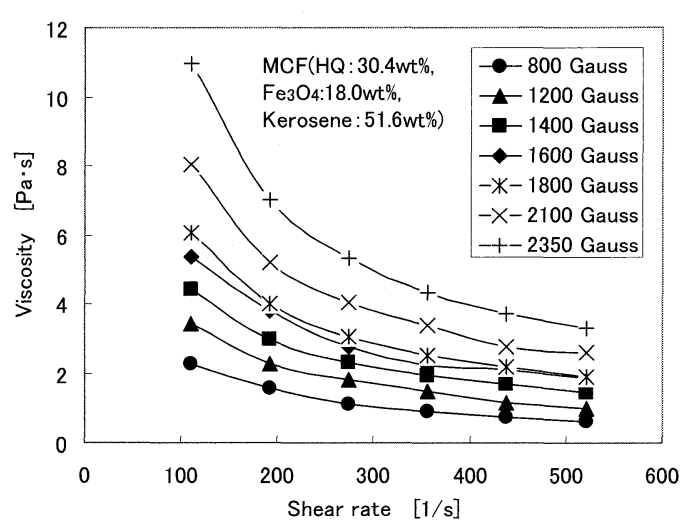

(b)

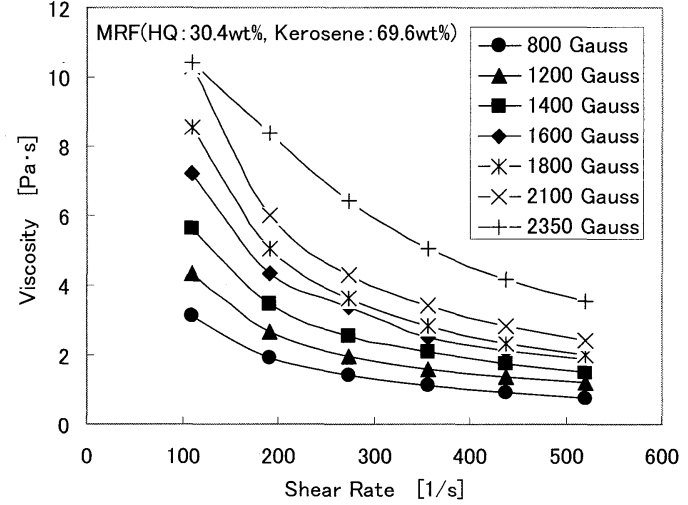

(c)

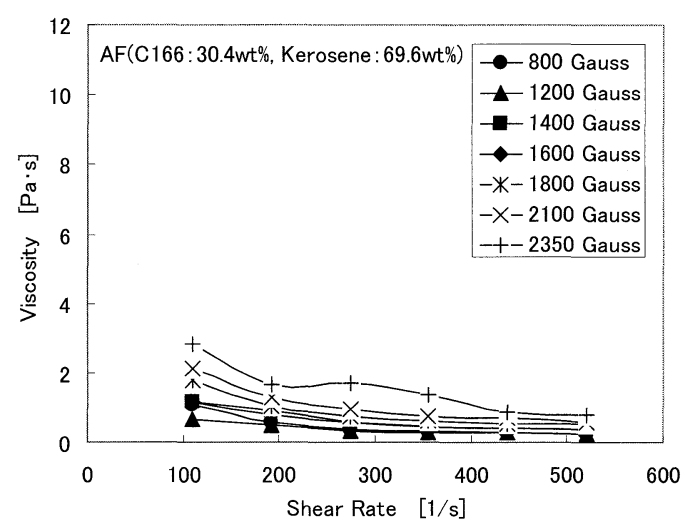

(d)

Figure 2 Viscosity to magnetic field intensity of (a) ACF, (b) MCF, (c) MRF and (d) AF

reported in our other investigation $[2,3]$. The experimental results are shown in Fig. 2 and compared to those of MCF, MRF and AF. The viscosity of ACF is less than that of MCF. This is due to the formation of magnetic clusters. As seen in the following section, the "string magnetic cluster" of ACM is weaker than the magnetic cluster of MCF. Therefore, the string-like magnetic cluster can be distributed by a given flow rate, and the viscosity of ACF then becomes less than that of $\mathrm{MCF}$.

\section{CLUSTER}

The particles involved in the ACF and other fluids are aggregated as clusters. The clusters can be extracted from ACF as well as from MCF and MRF using the technique proposed by Shimada [9]. A microscope photograph is shown in Fig. 3. The magnetic cluster of ACF differs from that of MCF. The length of the former is much larger than that of the latter, as shown by Fig. 1. In addition, the attractive strength between the particles of the former is much greater than that in the latter in the case when a force is immediately applied to the magnetic clusters in order to distribute each particle uniformly. Therefore, the magnetic cluster in ACF can 
be called a "string magnetic cluster." However, the force holding the cluster formation in the former is much larger than that in the latter if the applied magnetic field is removed from the magnetic clusters. This is due to the remnant magnetization, as shown in the previous section. After removing the magnetic field, the particles in $\mathrm{ACF}$, AMCF and AF can be held in a string-like cluster formation due to the remnant magnetization of the amorphous particles, as shown in Fig. 3(c-2), (d-2), and (e-2).

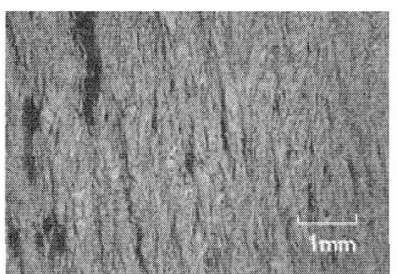

$(\mathrm{a}-1)$

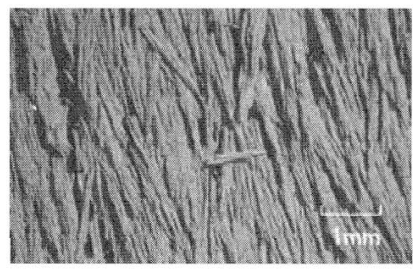

(b-1)
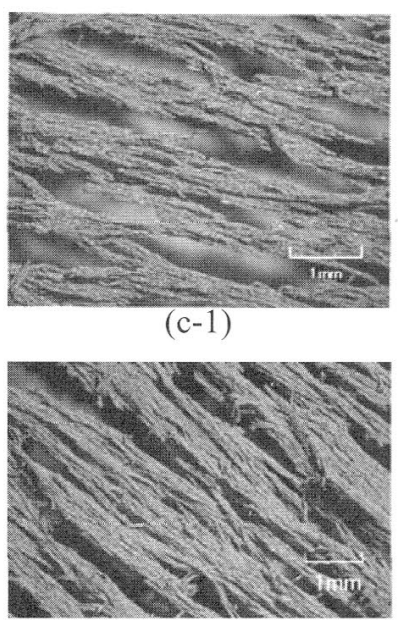

$(\mathrm{d}-1)$

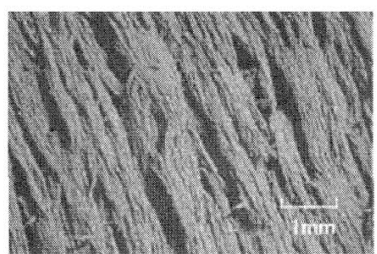

(e-1)

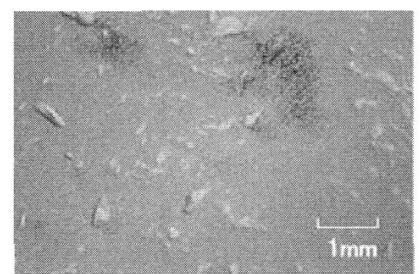

$(\mathrm{a}-2)$

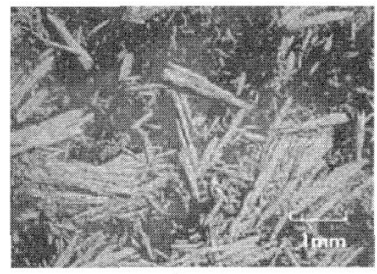

(b-2)

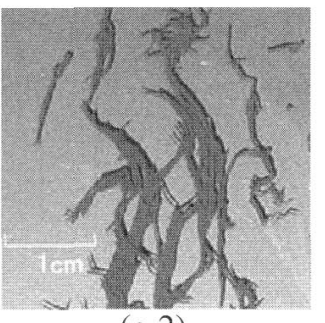

$(\mathrm{c}-2)$

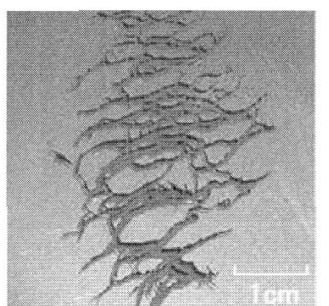

$(\mathrm{d}-2)$

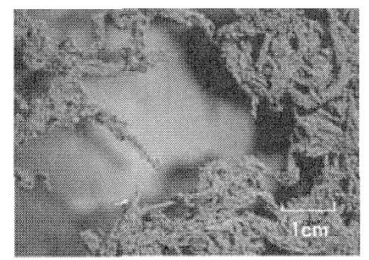

$(\mathrm{e}-2)$
Figure 3 Magnetic clusters of the fluids produced under a magnetic field as seen by a microscope with a multiplying ratio of 60: (a) MCF, (b) MRF, (c) ACF, (d) $\mathrm{AMCF}$, (e) AF; -1 indicates just after being removed from a magnetic field without any vibration, -2 indicates after being removed from a magnetic field and given a vibration

The particles involved in the ACF were observed by TEM, as shown in Fig. 4. Co and $\mathrm{P}$ are in the same position while $\mathrm{Fe}$ is in another position. Therefore, the $\mathrm{Fe}_{3} \mathrm{O}_{4}$ particles are surrounded by the amorphous particles. On the other hand, the amorphous particles are aggregated due to the remnant magnetization.

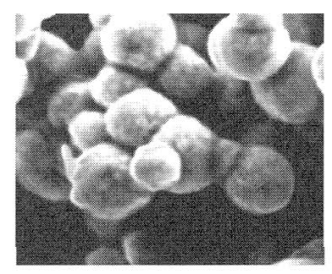

(a)

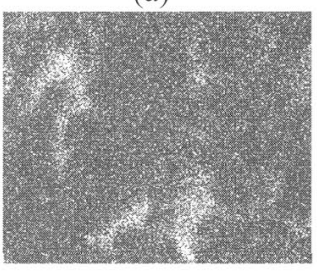

(c)

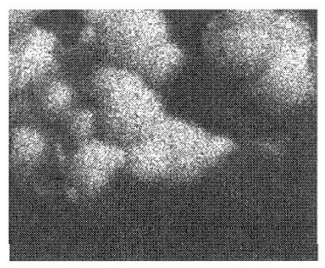

(b)

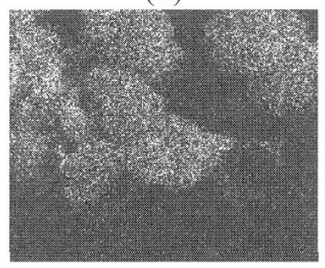

(d)
Figure 4 Photographs of ACF by TEM with a multiplying ratio of 10000: (a) all particles, (b) only Co, (c) only Fe, (d) only

\section{APPLICATIONS}

We tried to apply the ACF to polishing as one of its engineering applications. We used an experimental apparatus for float polishing, as shown in Fig. 5. A polishing tool having a permanent magnet with a diameter of $8 \mathrm{~mm}$ and maximum strength of 4500 Gauss was rotated by a drilling machine having a constant speed of $515 \mathrm{rpm}$. A disk type testing specimen made of brass having a diameter of $30 \mathrm{~mm}$ and thickness of 1 $\mathrm{mm}$ was attached to the surface of a lower load cell capsule. A testing fluid was inserted between the test specimen and the polishing tool. The load cell capsule was moved by the vibration machine with two types of motion, rotation and knitted brows rotation, having an amplitude of $10 \mathrm{~mm}$ and a frequency of $20 \mathrm{rpm}$. The clearance between the test specimen and the polishing tool was adjusted using an attachment to the vibration machine.

Table 2 shows the testing fluids of MCF and ACF used in the present study.

Figure 6 shows the surface roughness after polishing of $R a$ as (a) and of $R y$ as (b). The initial roughness $R a$ was $0.0923 \mu \mathrm{m}$ and the $R y$ was $0.616 \mu \mathrm{m}$. The polishing effect from using the ACF was a mirror-like surface, similar to the case of using the MCF. The cause of this 
result was the previously mentioned "string magnetic cluster": for ACF, as shown in Fig. 7(a), "string magnetic clusters" aggregated by amorphous and $\mathrm{Fe}_{3} \mathrm{O}_{4}$ particles function like a polishing cloth. ACF can polish more smoothly than MCF. On the other hand, MCF,

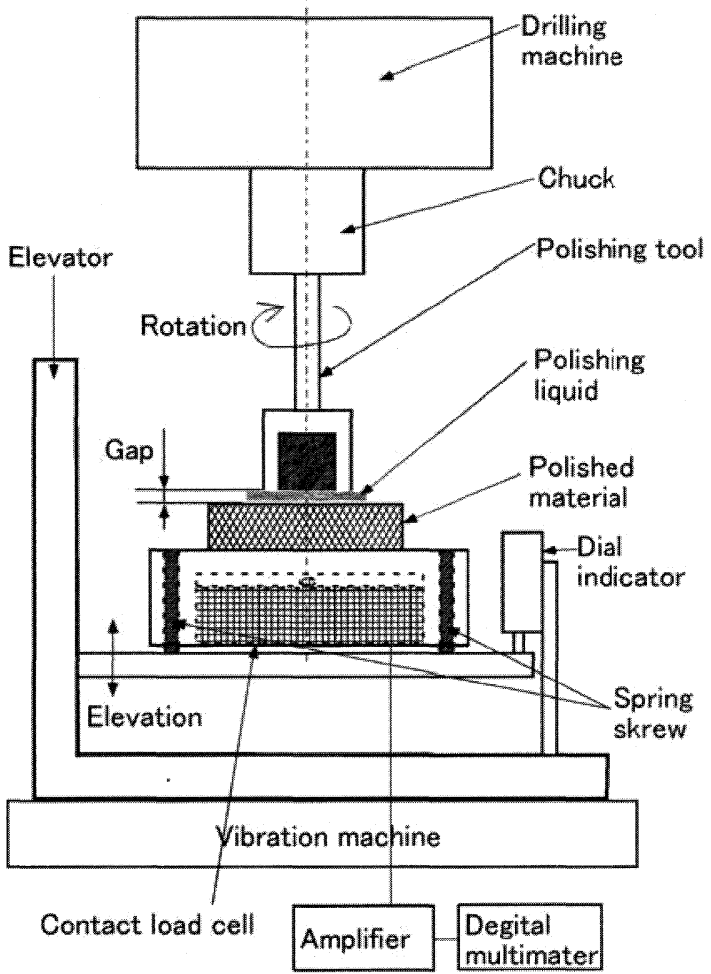

Figure 5 Schematic diagram of float polishing apparatus using the fluids

Table 2 Composite of MCF and ACF in float polishing

\begin{tabular}{|c|c|c|}
\hline $\begin{array}{l}\text { Testing } \\
\text { fluid }\end{array}$ & Components & $\begin{array}{c}\text { Mass } \\
\text { concentration }\end{array}$ \\
\hline $\mathrm{MCF}$ & $\begin{array}{l}\text { - } \mathrm{HQ}: 30 \mathrm{~g} \\
\text { - kerosene-baseed magnetic } \\
\text { fluid }(\mathrm{HC} 50(50 \mathrm{wt} \%)): \\
38.7 \mathrm{~g} \\
\text { - } \quad \text { kerosene }: 29 \mathrm{~g} \\
\text { - } \quad \text { abbrasive particle } \\
\left(\mathrm{Al}_{2} \mathrm{O}_{3}(3 \mu \mathrm{m})\right): 19.7 \mathrm{~g} \\
\text { - } \alpha \text {-cellurose }: 6.3 \mathrm{~g}\end{array}$ & $\begin{array}{l}\cdot \mathrm{HQ}: 24.3 \\
\mathrm{wt} \% \\
\cdot \mathrm{Fe}_{3} \mathrm{O}_{4}: 15.6 \\
\mathrm{wt} \%\end{array}$ \\
\hline $\mathrm{ACF}$ & $\begin{array}{l}\text { - } \mathrm{C} 166: 30 \mathrm{~g} \\
\text { - kerosene-baseed magnetic } \\
\text { fluid }(\mathrm{HC} 50(50 \mathrm{wt} \%)): \\
38.7 \mathrm{~g} \\
\text { - } \quad \text { kerosene : } 29 \mathrm{~g} \\
\text { - } \quad \text { abbrasive particle } \\
\quad\left(\mathrm{Al}_{2} \mathrm{O}_{3}(3 \mu \mathrm{m})\right): 19.7 \mathrm{~g} \\
\text { - } \alpha \text {-cellurose : } 6.3 \mathrm{~g}\end{array}$ & $\begin{array}{l}\cdot \mathrm{C} 166: 24.3 \\
\mathrm{wt} \% \\
\cdot \mathrm{Fe}_{3} \mathrm{O}_{4}: 15.6 \\
\mathrm{wt} \%\end{array}$ \\
\hline
\end{tabular}

with needle-like magnetic clusters aggregated by iron and $\mathrm{Fe}_{3} \mathrm{O}_{4}$ particles, polishes like a toothbrush, as shown in Fig. 7(b). Therefore, a mirror-like polished surface can be obtained by a polishing cloth with the ACF's clusters as well as by a polishing toothbrush with the MCF clusters.

Although the viscosity and saturation magnetization of ACF are smaller than those of MCF, the polishing effect of ACF is the same as that of MCF. The aggregated particle formation is a critical factor in the field of polishing. This result is very typical.

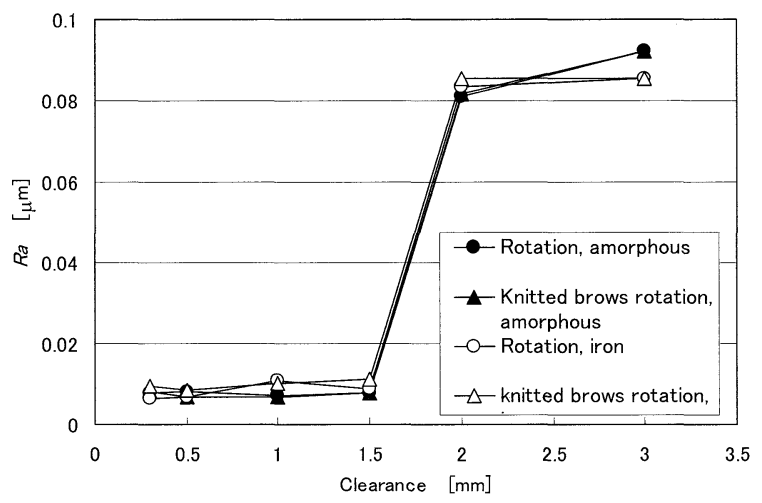

(a)

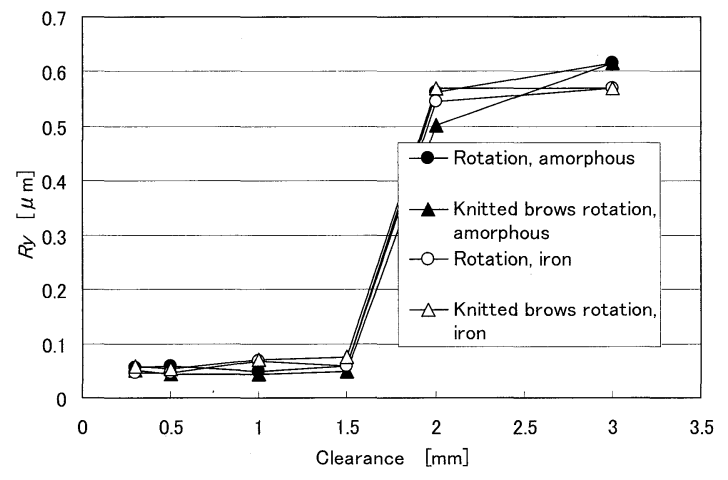

(b)

Figure 6 Surface roughness by float polishing utilizing $\mathrm{ACF}$ and MCF.

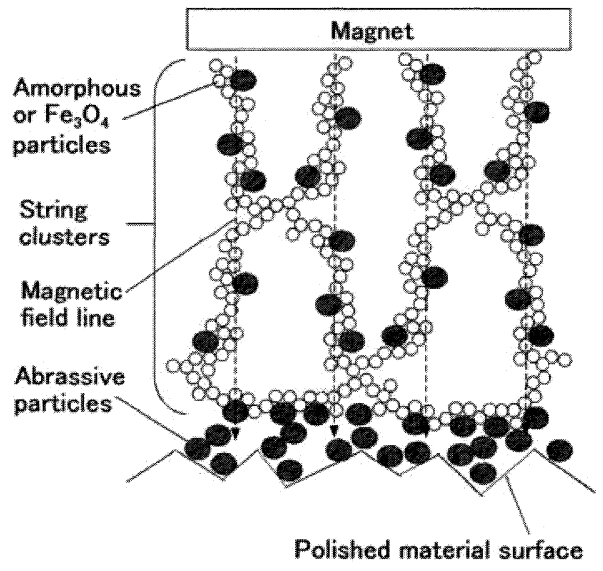

(a) 


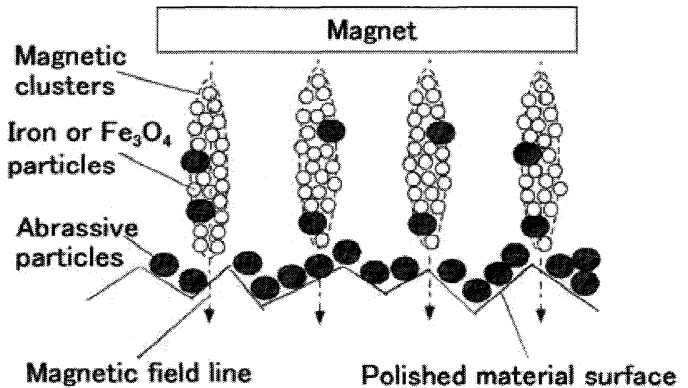

(b)

Figure 7 Schematic diagram of polishing model by string clusters in (a) ACF and (b) MCF

\section{CONCLUSION}

We proposed an amorphous compound fluid (ACF) as a new intelligent or smart fluid. We investigated the hydrodynamic characteristics of the fluid's viscosity and magnetic characteristics under a DC magnetic field. The viscosity and saturation magnetization of ACF are smaller than those of the previous magnetic responsive fluid, MCF, but its polishing effect is the same. The aggregated particle formation is a critical factor in the field of polishing.

\section{ACKNOWLEDGEMENT}

This work was partly supported by Grant-in-aid for Scientific Research: for Special Fields in 2004-2005 and Basic Research (C) in 2005. The authors are also very grateful to Prof. Ishio and Prof. Saito of Akita University for the measurement using V.S.M..

\section{REFERENCES}

1. Fujita, T. and Shimada, K., Characteristics and application of magnetorheological fluid, Recent Research Development Magnetism and Magnetic Materials, 2003, 1, pp.463-479.

2. Shimada, K., Akagami, Y., Fujita, T., Miyazaki, T., Kamiyama, S. and Shibayama, S., Characteristics of MCF (Magnetic Compound Fluid) in a rotating rheometer, J. Magn. Magn. Mat., 2002, 252, pp.235-237.

3. Shimada, K., Akagami, Y., Kamiyama, S., Fujita, T., Miyazaki, T. and Shibayama, A., New microscopic polishing with magnetic compound fluid (MCF), J. Intel. Mat. Sys. Struc., 2002, 13-7, pp.405-408.

4. Shimada, K. and Oka, H., Magnetic characteristics of magnetic compound fluid (MCF) under DC and AC magnetic fields, J. Magn. Magn. Mat., 2005, 290/291, pp. 804-807.

5. Shimada, K., Wu, Y., Wong, Y. C., Fujita, T., Miyazaki, T. and Shibayama, A., Experimental investigation of the effect of the MPL (magnetic polishing liquid) on surface finishing, Proc. SPIE,
2003, 4936, pp.312-320.

6. Shimada, K., Wu, Y. and Wong, Y. C., Effect of magnetic cluster and magnetic field on polishing using magnetic compound fluid (MCF), J. Magn. Magn. Mat., 2003, 262-2, pp.242- 247.

7. Shimada, K. Shuchi, S., Kanno, H., Wu., Y. and Kamiyama, S., Magnetic cluster and its applications, J. Magn. Magn. Mat., 2005, 289, pp.9-12.

8.Yuze, E., Matsuda, M. and Ohtsuka, K., Tokukai2000-87120, 2000, Japanese Patent.

9. Shimada, K., Miyazaki, T., Shibayama, A. and Fujita, T., Extraction of magnetic clusters self-assembled by a magnetic field, Smart Materials and Structures, 2003, 12-2, pp.297-303. 